\title{
Assessment of acute and sub-chronic neurotoxicity of Morus alba L. fruits in rodents
}

\author{
Arpita Paul, Anshul Shakya and Md Kamaruz Zaman*
}

\begin{abstract}
Background: Morus alba L. fruits are consumed since long for their nutritional and medicinal values. Although there were studies on the neuroprotective activity of the fruit extract, safety profile of the fruit extract is not yet explored as per the recommended standard guidelines over the central nervous system (CNS). The present work was aimed to assess the neurotoxicity profile of chemically characterized extract of M. alba L. fruits (MA) using validated OECD guidelines, i.e., 425 and 424 in rodents.

Results: Neurobehavioural parameters were examined for motor, sensory and behavioural responses using actophotometer, hot plate and light and dark box test, respectively as per OECD 424. Interestingly, no sign of mortality and/or adversity on mice treated per-orally with MA $(2000 \mathrm{mg} / \mathrm{kg})$ was observed during the limit test as per OECD 425. Further, rats treated with MA (1000, 300 and $100 \mathrm{mg} / \mathrm{kg}$, p.o.) for 28 days, showed insignificant ( $p<$ 0.05) changes in body weight, food consumption, neurobehavioural responses, organ weights and biochemical, haematological and histopathological features when compared with vehicle-treated animals.

Conclusion: The outcome of findings suggests that MA is safe in acute oral as well as sub-chronic (28 days) administration in mice and rats respectively. MA $(1000 \mathrm{mg} / \mathrm{kg})$ did not pose any toxic sign and symptoms on neurobehavioural responses in rats even after 28 days repeated treatment in compliance with OECD 424.
\end{abstract}

Keywords: Mulberry fruit, Functional food, Flavonoids, Neurotoxicity, Neurobehavioural response, Safety assessment

\section{Background}

Herbal medicine is the backbone of paramount healthcare system in the developing countries as the inhabitants of those areas do not have access or cannot afford to buy pharmaceuticals [1]. Many of these plants are used as medicine since time immemorial and are commonly perceived to be safe [2]. This safety is based on their long usage in the treatment of diseases according to the traditional knowledge accumulated over years. A general belief exist amongst people that herbal medicaments are exempted from any unwanted or toxic effects as they are derived from nature [3]. However, recent scientific studies have reported that many plant-derived

* Correspondence: kzaman71@dibru.ac.in

Department of Pharmaceutical Sciences, Faculty of Science and Engineering, Dibrugarh University, Dibrugarh, Assam 786004, India food and medicine are potentially toxic, mutagenic and carcinogenic [4,5]. Moreover, medicinal plants have not received much attention as its toxicity is not well established or is still unknown [6]. For these reasons, the toxicity study is a crucial part in assessment and development of herbal products.

Morus alba Linn. (Moraceae) is a perennial, deciduous medium-sized tree commonly known as white mulberry. It is native to Asian countries and is cultivated in certain tropical countries for rearing silkworms. The leaves are used to prepare different Indian recipes. The fruits are eaten as such, fermented to prepare special wine and beer and is made into jams and jellies [7]. Mulberry is not only used as a fruit but also as a medicine. In traditional oriental medicine, every part of the plant has diversified uses. In traditional Chinese medicine, mulberry 
is used for the treatment and prevention of different kinds of ailments like fever, and to protect the liver, improve eyesight, strengthen joints, facilitate discharge of urine and lower blood pressure [8]. The fruits possess cleansing properties and is used as mouth wash. It is used to treat anaemia, weakness, and fatigue, and to nourish the blood [9]. In contemporary pharmacological research, mulberry fruits are reported to have antioxidant and antimicrobial [10], diuretic [11], antibacterial [12], anti-diabetic [13], anti-parkinsonian [14, 15], and neuro-protective effect $[16,17]$ and is found to be effective against cerebral ischaemia [18]. Like other berries, mulberry fruits are rich in numerous bioactive constituents such as flavonoids, tannins, anthocyanins and phenolic acids which are known to have antioxidant properties [19]. These chemical constituents are found to have positive effects against the reported diseases and disorders. The fruits also contain ample amounts of ascorbic acid, carotene, vitamin D and minerals [20] that suggest its unique nutritional profile which enhances its significance as promising nature's functional tonic. $M$. alba is largely used as a nutraceutical that has led it to earn the status of 'superfood' [21]. Although there have been reports on the effectiveness of the fruit extract over the CNS-related etiologies, the safety profile of the fruit extract is yet to be explored as per the recommended standard guidelines over the CNS. Therefore, the objective of this investigation is to carry out acute toxicity study and to access sub-chronic neurotoxicity of mulberry fruit extract. The study was conducted in accordance to OECD guidelines.

\section{Methods}

\section{Collection and identification of the plant material}

The mature fruits of Morus alba L. were collected from the easternmost region of $\left(27^{\circ} 47^{\prime \prime}\right.$ latitude and $94^{\circ} 91^{\prime \prime}$ longitude), Assam, India, in the month of March 2018. The plant was identified and authenticated by the Eastern Regional Centre of the Botanical Survey of India (No.: BSI/ERC/2018/Tech/468, dated 22 October 2018).

\section{Preparation of the extract}

The fruits were washed thoroughly and dried under shaded condition. The dried material was subjected to pulverization and then passed through sieve no. 30 to get a coarse powder of the crude drug. The dried powder was extracted with $70 \%$ methanol by cold maceration at room temperature for $48 \mathrm{~h}$. The extract was filtered through Whatman no.1 filter paper. This was repeated for multiple times, and similar extracts were pooled together, concentrated and vacuum evaporated using rotary evaporator at a temperature of $45^{\circ} \mathrm{C}$, and the solvent traces were removed by lyophilization. The freeze-dried extract thus obtained was stored at low temperature $\left(-8^{\circ} \mathrm{C}\right)$ in air tight containers.

\section{High-performance thin layer chromatography analysis}

High-performance thin layer chromatography (HPTLC) analysis was performed using the markers quercetin, rutin and resveratrol. The reported contents of quercetin, rutin and resveratrol in mulberry fruits are $0.038,0.433$ and $0.03 \mathrm{mg} / \mathrm{g}$ of fruit extract respectively [19]. The standards $(1 \mathrm{mg} / \mathrm{ml})$ were prepared by dissolving $10 \mathrm{mg}$ of each of the standard (quercetin, rutin and resveratrol) in $10 \mathrm{ml}$ of methanol in separate volumetric flasks and were sonicated (Ultrasonic cleaner STD Rivotek, India).The extract was prepared by dissolving $100 \mathrm{mg}$ of $70 \%$ methanol extract of $M$. alba fruits in $1 \mathrm{~mL}$ methanol, sonicated followed by centrifugation (RM-03 Plus, REMI, India), and the supernatant was used for the analysis.

HPTLC was performed on silica gel $60 \mathrm{~F}_{254}$ pre-coated plates (Merck, Mumbai, India). The applications were made as bands $8.0-\mathrm{mm}$ wide, $11.5-\mathrm{mm}$ apart and 10.0 $\mathrm{mm}$ from the bottom edge of the chromatographic plate by the use of a Camag (Muttenz, Switzerland) Linomat $\mathrm{V}$ sample applicator equipped with a 100- $\mu \mathrm{L}$ Hamilton (USA) syringe. Ascending development to a distance of $70 \mathrm{~mm}$ was performed at room temperature $\left(28 \pm 2{ }^{\circ} \mathrm{C}\right)$, with a suitable mobile phase, in a Camag glass twintrough chamber previously saturated with mobile phase vapour for $20 \mathrm{~min}$. The mobile phases used as followsfor quercetin (toluene: ethyl acetate: formic acid: 10:8: 0.4), for resveratrol (hexane: ethyl acetate: glacial acetic acid: 8:12:0.2) and for rutin (ethyl acetate: formic acid: acetic acid: water: 15:1:1:1.5). After development, the plates were dried and then scanned at specified wavelength with a Camag TLC Scanner. The compounds were identified by superimposing the UV spectra of the standards and the samples within the same $R_{f}$ range.

\section{Animals and housing conditions}

The animal studies were performed in accordance with the guidelines of Committee for the Purpose of Control and Supervision of Experiments on Animals (CPCSEA) and was approved by the Institutional Animal Ethics Committee (IAEC), vide approval no. IAEC/DU/166, dtd. 10.12.2018. Female mice of Swiss strain $(20-25 \mathrm{~g})$ and male and female rats of Wistar strain $(150 \pm 20 \mathrm{~g}$, 5-6 weeks old), obtained from breeding house, were used for in vivo neurotoxicity study. The animal house was well ventilated, and the temperature was maintained at $22^{\circ} \mathrm{C}\left( \pm 3^{\circ} \mathrm{C}\right)$. Lighting was provided according to 12 $\mathrm{h}$ light/dark cycle. The animals were housed in large spacious cages in small groups of same sex to allow to acclimatize to laboratory conditions 5-7 days before the commencement of the experiment. For feeding, 
conventional laboratory diets were used with an unlimited supply of drinking water.

\section{Acute toxicity study}

The acute oral toxicity study was based on 'Up-andDown' procedure as described by Dixon according to OECD 425 guidelines [22]. Healthy adult female Swiss albino mice selected for the study were fasted overnight prior to dosing. MA extract was dissolved in $10 \%$ carboxymethyl cellulose (CMC) and administered orally at a single dose of $2000 \mathrm{mg} / \mathrm{kg}$ of body weight (b.w) to all the female mice $(n=6)$. Following the dosing, the animals were observed individually once, periodically during the first $24 \mathrm{~h}$ (with special attention given during the first $4 \mathrm{~h}$ ) and daily thereafter, for a total of 14 days for any delayed toxic effects. The behavioural changes and death were the main parameters observed during the study period.

\section{Neurotoxicity study}

The neurological safety profile of MA was evaluated by performing various neurobehavioural tests as per OECD guideline 424 [23]. Based on acute toxicity study result, three doses were selected for further studies $(1000,300$ and $100 \mathrm{mg} / \mathrm{kg}$ ). The control group animals received a definite volume of distilled water. Accordingly, the animals were randomly divided into 4 groups (comprising $n$ $=12$ animals; 6 males and 6 females in each group). Repeated daily dose of design regimen was administered orally for a period of 28 days.

\section{Neurobehavioural evaluation}

Neurotoxicity of the plant was determined using open field test on actophotometer for motor coordination and ataxia, sensory response analysis using hot plate test and stereotyped behaviour (rearing, grooming, latency, level of mobility, urination/defecation, tremor/convulsions, vocalization, arousal, posture, pilo-erection, gait abnormalities, stereotypy and/or unusual behaviours) using light-dark box test.

\section{Assessment of motor dysfunction Spontaneous locomotor activity}

The locomotor activity can be an index of wakefulness (alertness) of mental activity. The spontaneous locomotor activity was performed in actophotometer (Orchid Scientific \& Innovative India Pvt. Ltd., Nashik, India). Each animal was allowed for a period of $5 \mathrm{~min}$ in a square closed field arena $(30 \times 30 \times 30 \mathrm{~cm})$ equipped with 6 photocells in the outer wall for spontaneous locomotion. Interruption of photocell beams (locomotor activity) was recorded by means of a 6 digit resettable counter. Increase in count was regarded as central nervous stimulation, decrease in count as central nervous depressant activity [24].

\section{Assessment of behavioural impairment Light-dark box test}

The light-dark box (LDB) (Orchid Scientific \& Innovative India Pvt. Ltd., Nashik, India) setup consisted of two compartments: one lit compartment $(40 \times 50 \mathrm{~cm}, 350$ lux; light box $)$ and one dark compartment $(40 \times 30 \mathrm{~cm}$, 70 lux) [25]. The floors in each compartment were divided into squares $(10 \times 10 \mathrm{~cm})$, and the compartments were connected via a small opening $(7.5 \times 7.5 \mathrm{~cm})$ enabling transition between the compartments [26]. Rats were placed in the dark compartment and rearing and grooming, number of entries and time spent in light compartment, and latency to first light compartment entry during the $5 \mathrm{~min}$ test were assessed by all maze video tracking software (Orchid Scientific \& Innovative India Pvt. Ltd., Nashik, India).

\section{Assessment of sensory dysfunction Hot plate reaction time in rats}

Rats were screened by placing them on a hot plate maintained at $55 \pm 1{ }^{\circ} \mathrm{C}$ and recording the reaction time in seconds for forepaw licking or jumping. Only animals which reacted within $15 \mathrm{~s}$ and which did not show large variation when tested on four separate occasions, each 15 min apart, were taken for the test. The time for forepaw licking or jumping on the heated plate of the analgesiometer maintained at $55^{\circ} \mathrm{C}$ was taken as the reaction time [24].

\section{Body weight and food consumption}

All animals were weighed once a week. The food intake was also recorded weekly.

\section{Biochemical and haematological analysis}

At 28th day of the treatment, blood samples were collected from the animals in two batches. From one batch of blood sample, serum was separated by centrifuging at $6000 \mathrm{rpm}$ for $10 \mathrm{~min}$ and was used for biochemical investigations. The other batch was used for haematological study.

\section{Necroscopy and histopathology}

After euthanasia, the internal organs (liver, spleen, lung, heart, kidneys, testis and ovaries) were harvested, and gross findings as well as organ weights were recorded. The liver, spleen, lung, heart, kidney and brain were fixed with neutral formalin for $48 \mathrm{~h}$, dehydrated with alcohol, embedded in paraffin, cut into thin sections and stained with haematoxylin-eosin dye for photomicroscopic examinations. 


\section{Statistical analysis}

Data of all experiments were expressed as mean \pm Standard deviation (SD) of six animals in each group. Differences amongst different treatment groups were determined by one-way analysis of variance (ANOVA) followed by Student-Newman-Keuls comparison test unless stated otherwise. GraphPad Prism 5 was used for statistical analysis.

\section{Results}

\section{HPTLC analysis}

The MA extract was characterized by validated HPTLC method [27, 28]. The identification of quercetin was confirmed by superimposing the UV spectra of the standard and the sample within the same $R_{f} \sim 0.334$ at $262 \mathrm{~nm}$ (Fig. 1a). Similarly, the UV spectra of standard rutin was found to match with that of sample within the same $R_{f} 0.235$ at $262 \mathrm{~nm}$ (Fig. 1b). The presence of resveratrol in the sample was confirmed when its $R_{f}$ at 0.566 was found to match with that of the standard at $302 \mathrm{~nm}$ (Fig. 1c).

\section{Acute toxicity study}

Rats administered with a single per-oral dose of MA at $2000 \mathrm{mg} / \mathrm{kg}$ did not show any toxic signs and/or mortality during the period of observation (14 days) as per OECD 425. Therefore $\mathrm{LD}_{50}$ (median lethal dose: dose required to kill half of the tested population after a specified test duration) of MA was found to be more than $2000 \mathrm{mg} / \mathrm{kg}$ as calculated by AOT425statpgm (ver.1.0).

\section{Neurotoxicity study}

\section{Mortality and clinical signs}

All administration groups survived to the end of study, and no obvious abnormal clinical signs were found in any of the MA-treated groups, throughout the experimental period of 28 days. No obvious clinical sign, including loss of hair, changes in skin colour, scabbing, eyes and mucous membranes and change in behaviour patterns were observed in any of the treated groups throughout the experimental period. The animals from all administration groups appeared healthy throughout the study period.

\section{Neurobehavioural assessment}

\section{Assessment of motor dysfunction}

Spontaneous locomotor activity The $M$. alba-treated groups did not produce any significant $(P<0.05)$ increase or reduction in locomotor activity when compared with the vehicle control group. The results of the test are given in Fig. 2.

\section{Assessment of behavioural impairment}

Light-dark box test The animals treated with MA did not show any significant $(P<0.05)$ change in the time spent in light chamber and the number of entries in light chamber. The results of $L \& D$ box test are given in Fig. 3.

\section{Assessment of sensory dysfunction}

Hot plate reaction time in rat The reaction time of the $\mathrm{MA}$ at the doses of 100,300 and $1000 \mathrm{mg} / \mathrm{kg}$ produced no significant change in the reaction time in the hot plate $(P<0.05)$ (Fig. 4$)$.

\section{Body weight and food consumption}

There were no changes in body weights in the treated groups when compared to the vehicle control group. Body weight changes for male and female rats during the treatment periods are given in the Fig. 5. The treatment did not affect the daily food consumption. The report of food consumption during the course of the treatment is given in Fig. 6.

\section{Biochemical and haematological analysis}

The effects of administration of MA on haematological and biochemical parameters are presented in Tables 1 and 2. There are no significant changes in haematological parameters (haemoglobin, total RBC cells, total WBC cells and haematocrit) of treated rats and the control group. No statistically significant changes in kidney function parameters (blood urea nitrogen, creatinine) were noted. The liver function enzymes such as alanine aminotransferase (ALT), aspartate aminotransferase (AST) and alkaline phosphatase did not reveal any relevant changes in the extract-administered groups. The reports of total protein, cholesterol, glucose and albumin level did not indicate any notable changes.

\section{Organ weight}

Organ weights of 28 days treated-groups are shown in Table 3. No significant difference in organ weight was observed in the treatment and control groups at the time of necroscopy.

\section{Histopathology}

Histopathological examinations were first conducted on the liver, kidneys, heart, spleen, lungs, brain, pancreas and stomach of animals only in the high-dose and control groups. If there were pathological changes observed, histological examination of the corresponding organs were also carried out in the mid-dose and low-dose groups. Macroscopic examination of the organs of animals treated with high dose did not reveal any 


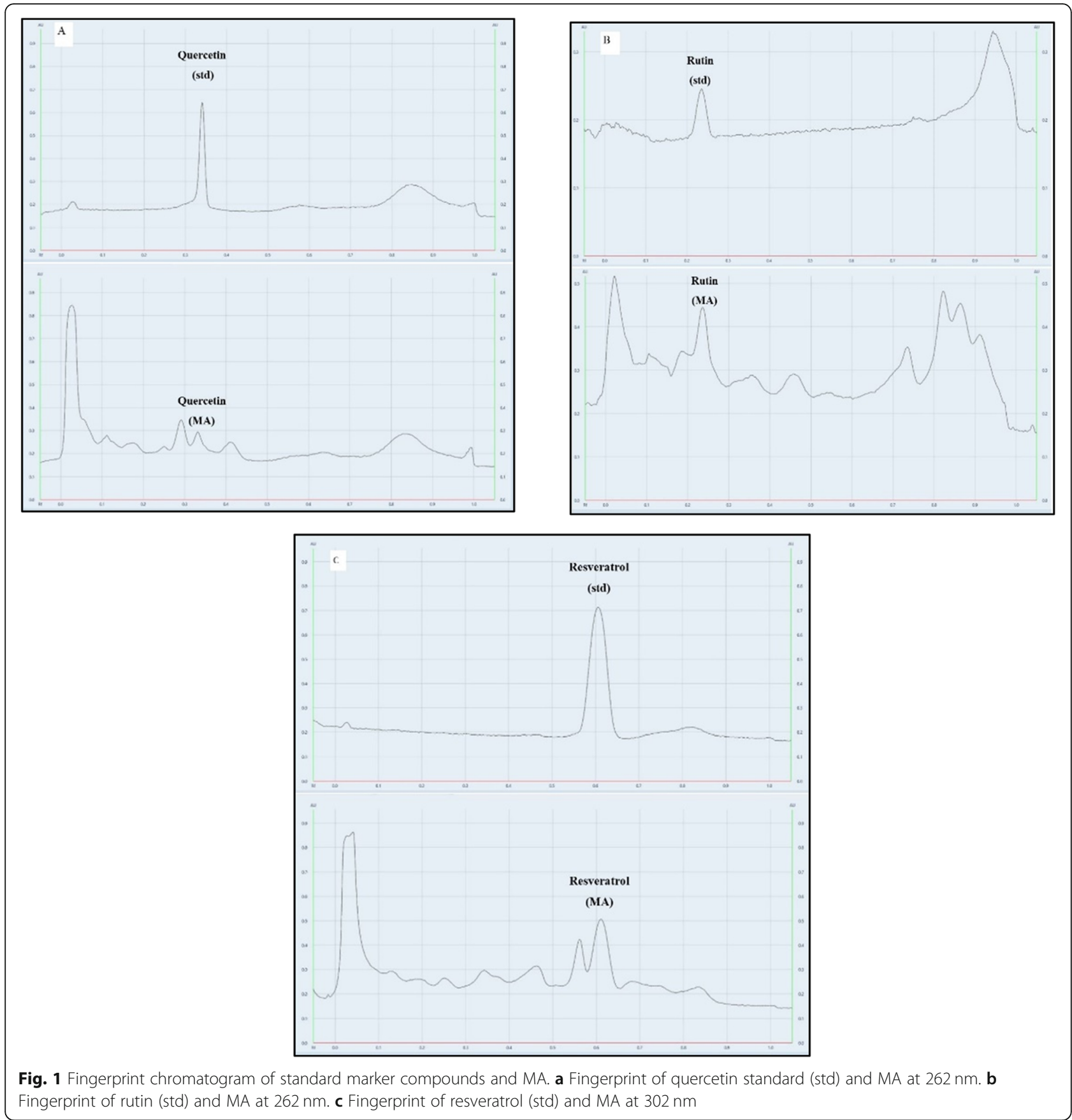

abnormality in colour or texture when compared with the organs of the control group. In addition, microscopic examination of the control and MA-treated group showed normal architecture and absence of any gross pathological lesion in organs (Fig. 7).

\section{Discussion}

As the global use and commercial success of medicines, nutraceuticals and functional foods have grown, so have concerns about public health risks regarding the concentration, composition, and individual contaminants, as well as their interactions with other drugs [29]. In traditional system of medicine, mulberry fruits are useful in the treatment of anaemia, weakness and fatigue and nourish the blood [9]. Although previous studies have attested that the fruits of the plant produce beneficial effect over the CNS $[14,17,18]$ there is no regulatory neuro-toxicological evaluation on mulberry fruit extract. In addition, both medicinal and poisonous plants possess secondary metabolites such as glycosides, 


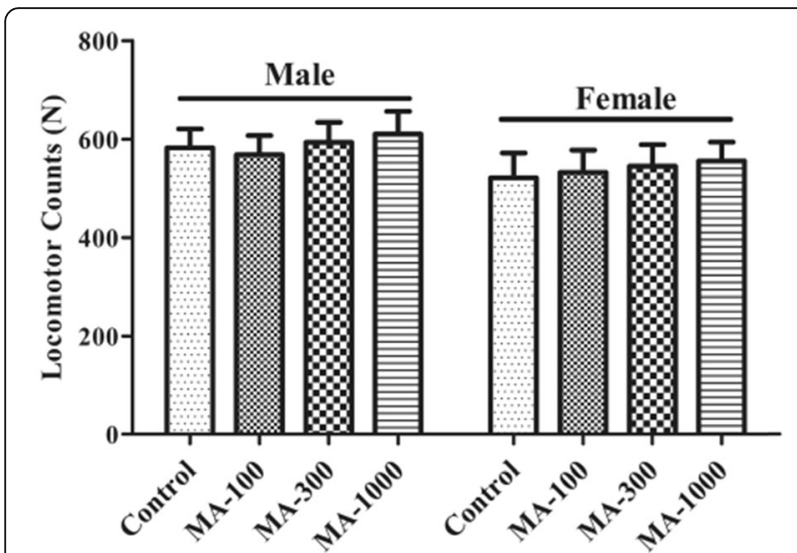

Fig. 2 Effect of MA (100, 300 and $1000 \mathrm{mg} / \mathrm{kg} / \mathrm{b} . w$.$) on locomotor$ counts in actophotometer test. Values are mean $\pm S D, n=6$ animals in each group. $P$ value $(P<0.05)$ was considered as statistically significant. Data was analyzed via one-way ANOVA followed by Newman-Keuls Multiple Comparison Test

alkaloids, flavonoids, tannins and amino acids [30] and exhibit beneficial or adverse effects based on it [31]. As safety is the preponderant measure in the selection of herbal products for use in healthcare systems, [32] here, the neuro-toxicity of $M$. alba fruit extract was evaluated as per standard guidelines.

In the present study, MA was characterized by HPTL $\mathrm{C}$ method using quercetin, rutin and resveratrol as markers. The effects of MA on behavioural paradigms, biochemical, haematological and architectural changes were evaluated. Mortality is an important criterion in toxicity evaluation [33], and acute administration did not elicit significant mortality. No deaths occurred within $48 \mathrm{~h}$. No clinical signs of toxicity occurred, and all the animals appeared to be healthy. From acute toxicity study, the $\mathrm{LD}_{50}$ value of the MA was found to be greater than $2000 \mathrm{mg} / \mathrm{kg}$.

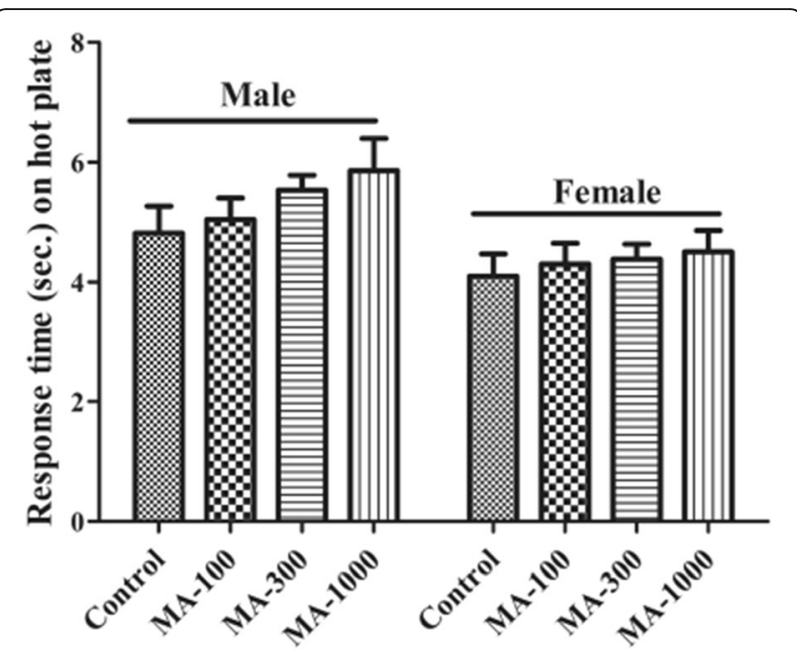

Fig. 4 Response time on hot plate test on male and female rats. Values are mean $\pm \mathrm{SD}, n=6$ animals in each group. $P$ value $(P<$ $0.05)$ was considered as statistically significant. Data was analyzed via one way ANOVA followed by Newman-Keuls Multiple Comparison Test

The CNS controls all the major functions of the body, and minor alterations of the nervous system can have a profound impact on other activities of the body. Behaviour is considered as an important manifestation of the CNS, and any toxicant-induced alterations of the CNS are reflected in the neurobehavioural output of the animal. Thus, the OECD guideline 424 states that there are several other signs of nervous system toxicity other than neuropathy such as loss of motor coordination, sensory deficits and behavioural dysfunction. So, to detect the major neurobehavioural effects of $M$. alba in vivo, we used certain neuro-pharmacological models to characterize and quantify the neurotoxic responses which is further supported by histopathological,
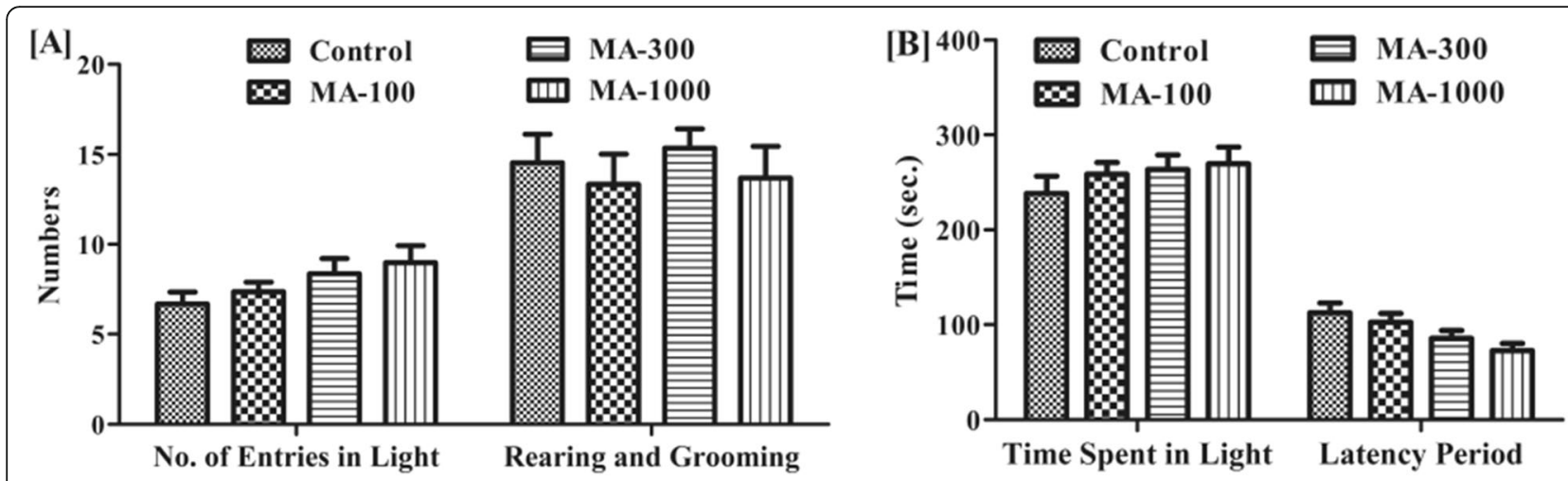

Fig. 3 Effect of MA (100, 300 and 1000 mg/kg/b.w.) on behavioural impairment of rats using light-dark box test. a Number of entries in light chamber and rearing and grooming score; $\mathbf{b}$ time spent in light and latency period of first time entry in light chamber on rats. Values are mean $\pm \mathrm{SD}, n=12$ animals in each group. $P$ value $(P<0.05)$ was considered as statistically significant. Data was analyzed via one-way ANOVA followed by Newman-Keuls Multiple Comparison Test 

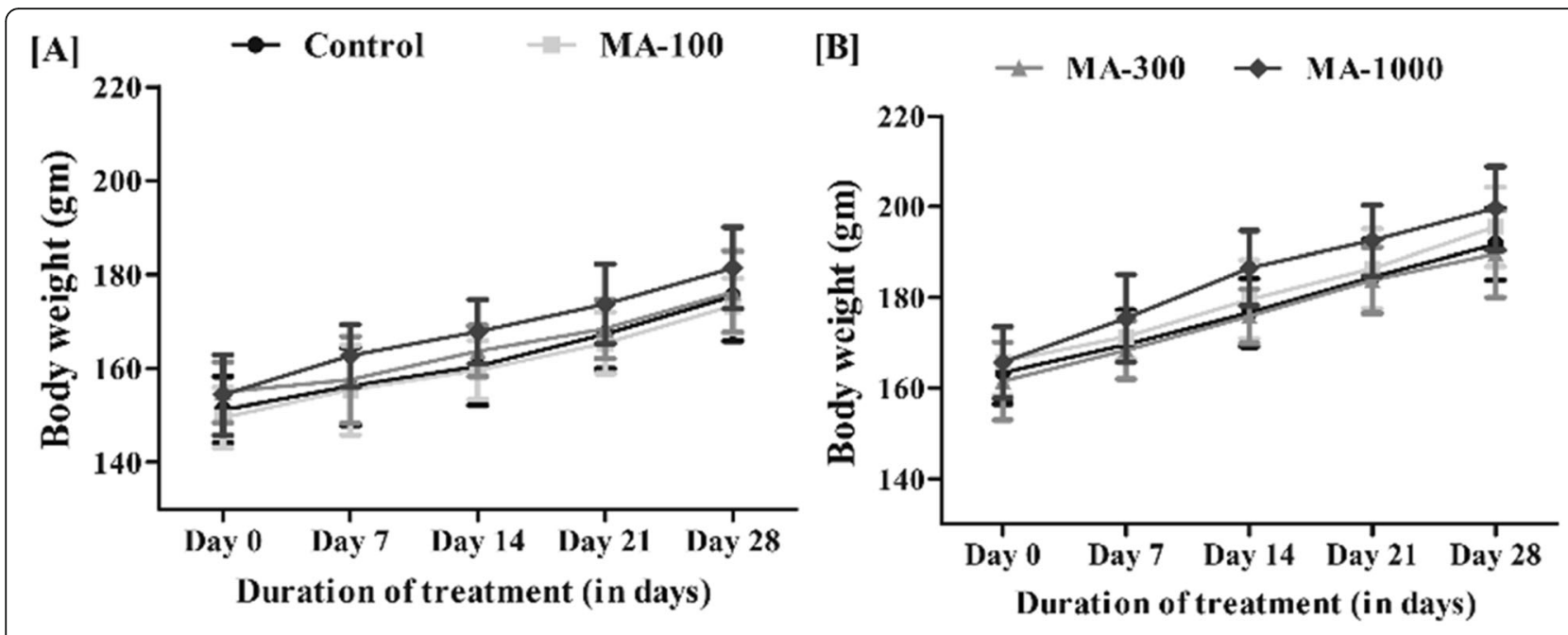

Fig. 5 Changes in body weight of rats treated with MA for a period of 28 days. a Male rats and $\mathbf{b}$ female rats. The values were presented as mean \pm SD

haematological and biochemical investigations. Locomotor activity is considered as an index of alertness and a decrease in it is an indicative of sedative activity [34]. The locotomotor activity was assessed by actophotometer test, and the number of locomotor counts of the treated animals did not vary significantly $(P<0.05)$ from the control animals. The light and dark paradigm is based on the natural aversion of rodent to brightly lit places. In this model, the treated animals showed no variation $(P<0.05)$ in the time spent in the light and dark compartments compared to the vehicle control animals. In this study, the hotplate method was used to establish the effectiveness of the extract in evaluating the CNS analgesia. In this model, the reaction time of MA-treated animals on the hotplate did not indicate any remarkable difference from that of the vehicle-treated animals.

Changes in the body weight are an important indicator in the determination of physiological changes brought about by the ingestion of an external agent [35]. Repeated administration of MA did not cause any change in body weights of the animals in the treatment groups $(100,300,1000 \mathrm{mg} / \mathrm{kg})$.

The daily food and water intake of the treated animals did not vary significantly in both the sexes compared to control animals. This indicates that MA did not interfere with the normal metabolism and so with the general health status of the treated animals. Similarly, no biological significant variation in the weights of the liver,
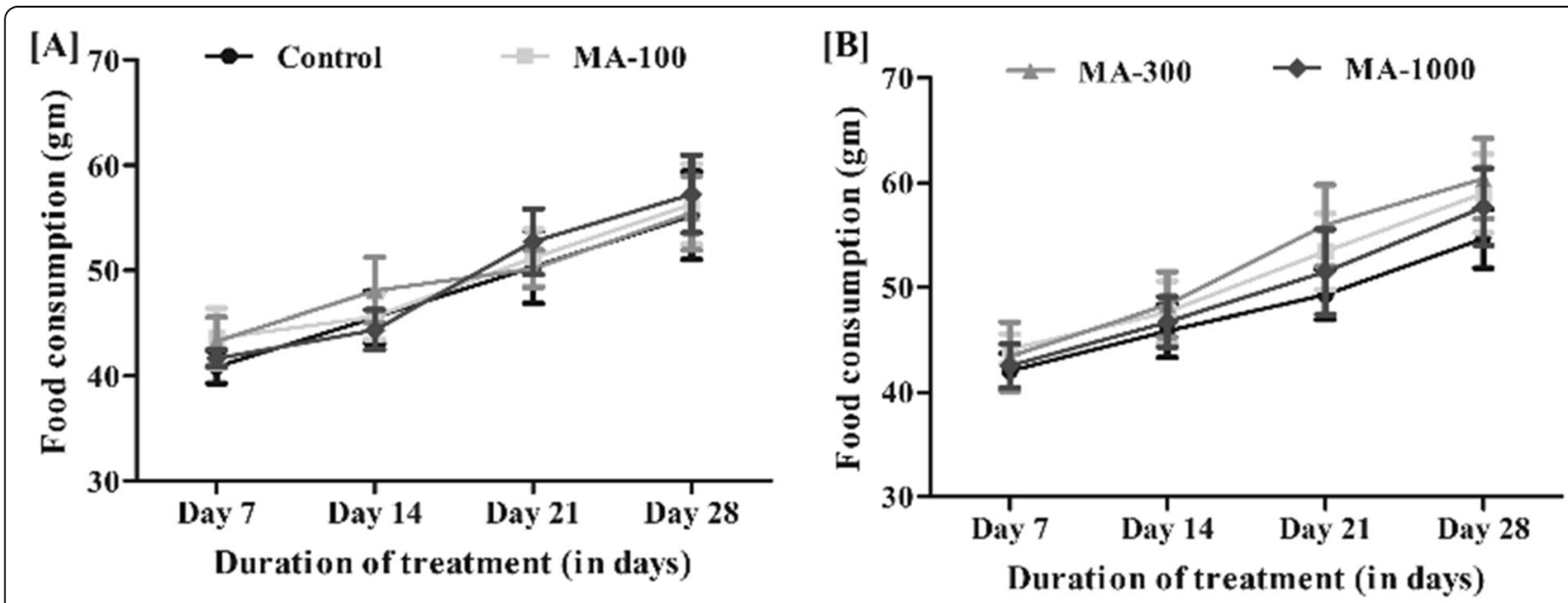

Fig. $\mathbf{6}$ Changes in food consumption of rats treated with MA for a period of 28 days. a Male rats and $\mathbf{b}$ female rats. The values were presented as mean \pm SD 
Table 1 Haematological parameters of rats treated with 100, 300 and $1000 \mathrm{mg} / \mathrm{kg}$ of MA for a period of 28 days

\begin{tabular}{|c|c|c|c|c|c|c|}
\hline \multirow{2}{*}{$\frac{\text { Treatment }}{\text { Control }}$} & \multicolumn{2}{|c|}{ Dose (mg/kg, p.o.) } & \multirow{2}{*}{$\frac{\mathrm{RBC}\left(\times 10^{6} / \mu \mathrm{l}\right)}{7.24 \pm 0.56}$} & \multirow{2}{*}{$\begin{array}{l}\text { WBC }\left(\times 10^{3} / \mu \mathrm{l}\right) \\
9.42 \pm 0.28\end{array}$} & \multirow{2}{*}{$\begin{array}{l}\text { Haemoglobin }(\mathbf{g m} / \mathbf{d l}) \\
12.78 \pm 1.08\end{array}$} & \multirow{2}{*}{$\frac{\text { Haematocrit(\%) }}{42.0 \pm 0.6}$} \\
\hline & -- & Female & & & & \\
\hline MA & 100 & & $7.31 \pm 0.34$ & $8.92 \pm 0.26$ & $13.20 \pm 1.12$ & $41.0 \pm 0.8$ \\
\hline MA & 300 & & $7.36 \pm 0.30$ & $9.04 \pm 0.14$ & $12.76 \pm 1.06$ & $43.0 \pm 1.2$ \\
\hline MA & 1000 & & $7.28 \pm 0.42$ & $9.28 \pm 0.44$ & $13.08 \pm 1.32$ & $42.0 \pm 1.6$ \\
\hline Control & -- & Male & $7.81 \pm 0.56$ & $8.94 \pm 0.36$ & $14.86 \pm 0.98$ & $44.0 \pm 0.7$ \\
\hline MA & 100 & & $7.64 \pm 0.34$ & $9.08 \pm 0.22$ & $14.54 \pm 1.22$ & $43.0 \pm 1.2$ \\
\hline MA & 300 & & $7.50 \pm 0.30$ & $8.88 \pm 0.42$ & $15.02 \pm 1.30$ & $43.0 \pm 1.4$ \\
\hline MA & 1000 & & $7.82 \pm 0.42$ & $9.10 \pm 0.34$ & $14.50 \pm 1.45$ & $44.0 \pm 0.8$ \\
\hline
\end{tabular}

Values are mean \pm SD. There was no significant change in blood profile of rats during treatment

$R B C$ red blood cell count, WBC white blood cell count, $n=6$

spleen, lung, heart, kidneys, testis/ovary or brain was observed, suggesting that the administration of the extract at the sub-chronic oral doses had no effect on normal growth. Since there was no reduction in body and organ weights of the treated animals at any of the doses tested, we concluded that the extract is nontoxic to the analyzed organs.

The haemopoietic system is considered one of the most sensitive target for the toxic compounds, and its effects can cause changes in the normal counts of blood components [36]. The haematological parameters did not show any relevant changes in the MA-treated animals. This indicates that MA did not interfere with haematopoiesis and leucopoiesis in rats.

The liver is the main site of detoxification, and liver damage is assessed by determination of serum transaminases and total protein [37]. The lack of alterations in the levels of enzymes (AST and ALT), used as biomarkers for predicting toxicity [38], indicates MA did not cause any detrimental effects to the liver. The renal function markers, blood urea nitrogen and creatinine levels, were not affected by administration of the extract. The liver is the major site of cholesterol synthesis and degradation [39]. Since, no relevant changes were observed in the levels of cholesterol, it indicates MA had no effects on the cholesterol metabolism in rats. The other biochemical parameters, glucose and albumin levels, were also found to be normal. These results were further supported by the histopathological examinations.

The macroscopic analysis did not show any abnormal changes. In addition, the microscopic examination of selected vital organs from high-dose $(1000 \mathrm{mg} / \mathrm{kg})$ treated and control animals revealed normal architecture. The animals had normal hepatocytes, portal vein, glomeruli, intact alveolar sac, cardiac cells, brain cells, pancreatic cells and stomach walls. Thus, histological studies confirmed that no internal injuries or morphological changes were triggered by daily oral administration of MA extract for a period of 28 days, even at the highest tested dose of $1000 \mathrm{mg} / \mathrm{kg}$.

\section{Conclusion}

Neurotoxicological profile of chemically characterized MA extract was carried out to evaluate the safety of MA over the CNS. The result of the overall investigation suggest that the fruits of Morus alba L. do not possess any toxicologically relevant abnormalities over the CNS even at the highest dose of $1000 \mathrm{mg} / \mathrm{kg}$. The present study is carried out based upon the behavioural models without

Table 2 Biochemical parameters of rats treated with (100,300, $1000 \mathrm{mg} / \mathrm{kg})$ MA for a period of 28 days

\begin{tabular}{|c|c|c|c|c|c|c|c|c|c|c|}
\hline Treatment & $\begin{array}{l}\text { Dose } \\
\text { (mg/kg, p.o.) }\end{array}$ & $\begin{array}{l}\text { Glucose } \\
\text { (mg/dl) }\end{array}$ & $\begin{array}{l}\text { Cholesterol } \\
\text { (mg/dl) }\end{array}$ & AST (U/L) & ALT (IU/L) & $\begin{array}{l}\text { Alkaline } \\
\text { phosphatase } \\
\text { (U/L) }\end{array}$ & $\begin{array}{l}\text { Blood urea nitrogen } \\
\text { (mg/dl) }\end{array}$ & $\begin{array}{l}\text { Creatinine } \\
(\mathrm{mg} / \mathrm{dl})\end{array}$ & $\begin{array}{l}\text { Total } \\
\text { protein } \\
(\mathrm{gm} / \mathrm{dl})\end{array}$ & $\begin{array}{l}\text { Albumin } \\
\text { (gm/dl) }\end{array}$ \\
\hline Control & Female & $113.78 \pm 8.46$ & $77.34 \pm 3.38$ & $94.30 \pm 7.54$ & $38.68 \pm 2.08$ & $53.54 \pm 3.06$ & $18.74 \pm 1.36$ & $4.22 \pm 0.34$ & $7.02 \pm 0.46$ & $2.92 \pm 0.24$ \\
\hline MA & 100 & $110.32 \pm 9.60$ & $81.04 \pm 3.86$ & $93.66 \pm 6.24$ & $40.42 \pm 2.16$ & $56.20 \pm 2.86$ & $17.92 \pm 2.08$ & $3.88 \pm 0.30$ & $6.84 \pm 0.48$ & $3.10 \pm 0.28$ \\
\hline MA & 300 & $114.64 \pm 7.36$ & $78.54 \pm 4.12$ & $90.56 \pm 7.92$ & $41.86 \pm 1.98$ & $54.82 \pm 4.64$ & $18.28 \pm 1.62$ & $4.16 \pm 0.26$ & $6.78 \pm 0.54$ & $2.88 \pm 0.32$ \\
\hline MA & 1000 & $111.28 \pm 8.32$ & $80.46 \pm 3.78$ & $93.94 \pm 8.60$ & $40.88 \pm 2.24$ & $52.80 \pm 3.66$ & $19.01 \pm 1.28$ & $4.24 \pm 0.32$ & $6.88 \pm 0.76$ & $2.94 \pm 0.34$ \\
\hline Control & Male & $114.12 \pm 5.54$ & $54.56 \pm 2.68$ & $88.34 \pm 5.32$ & $28.38 \pm 1.26$ & $93.66 \pm 6.54$ & $16.86 \pm 1.92$ & $3.60 \pm 0.28$ & $6.03 \pm 0.32$ & $2.44 \pm 0.26$ \\
\hline MA & 100 & $112.70 \pm 6.72$ & $52.90 \pm 3.04$ & $90.04 \pm 4.78$ & $26.86 \pm 1.80$ & $98.92 \pm 7.84$ & $16.44 \pm 1.56$ & $3.26 \pm 0.24$ & $5.98 \pm 0.38$ & $2.56 \pm 0.30$ \\
\hline MA & 300 & $113.56 \pm 4.60$ & $50.46 \pm 3.86$ & $89.58 \pm 5.82$ & $30.56 \pm 1.66$ & $94.92 \pm 6.80$ & $15.98 \pm 1.36$ & $3.56 \pm 0.32$ & $6.12 \pm 0.82$ & $2.60 \pm 0.42$ \\
\hline MA & 1000 & $115.70 \pm 7.32$ & $51.52 \pm 2.62$ & $87.76 \pm 4.68$ & $31.04 \pm 1.14$ & $91.26 \pm 8.36$ & $16.04 \pm 1.60$ & $3.32 \pm 0.28$ & $6.10 \pm 0.35$ & $2.72 \pm 0.38$ \\
\hline
\end{tabular}

Values are mean \pm SD. There was no significant change in biochemical parameters of rats during treatment

AST aspartate transaminase, $A L T$ alanine transaminase, $n=6$ 
Table 3 Organ weights of rats administered orally with MA for a period of 28 days

\begin{tabular}{|c|c|c|c|c|c|c|c|c|c|c|c|}
\hline \multirow[t]{3}{*}{ Treatment } & \multirow{3}{*}{\multicolumn{2}{|c|}{$\begin{array}{l}\text { Dose }(\mathrm{mg} / \mathrm{kg} \text {, } \\
\text { p.o.) }\end{array}$}} & \multicolumn{9}{|c|}{ Organ weight(gm) } \\
\hline & & & \multirow[t]{2}{*}{ Liver } & \multirow[t]{2}{*}{ Lungs } & \multirow[t]{2}{*}{ Brain } & \multirow[t]{2}{*}{ Heart } & \multirow[t]{2}{*}{ Spleen } & \multicolumn{2}{|l|}{ Kidney } & \multicolumn{2}{|l|}{ Testis/ovary } \\
\hline & & & & & & & & $\mathrm{L}$ & $\mathbf{R}$ & $\mathrm{L}$ & $\mathbf{R}$ \\
\hline Control & $-3-$ & Female & $6.56 \pm 0.30$ & $0.73 \pm 0.08$ & $1.98 \pm 0.06$ & $1.33 \pm 0.05$ & $0.73 \pm 0.05$ & $0.83 \pm 0.05$ & $0.76 \pm 0.05$ & $1.26 \pm 0.15$ & $1.26 \pm 0.05$ \\
\hline MA & 100 & & $5.33 \pm 0.25$ & $0.63 \pm 0.05$ & $1.90 \pm 0.06$ & $1.27 \pm 0.15$ & $0.72 \pm 0.26$ & $0.83 \pm 0.20$ & $0.66 \pm 0.20$ & $1.33 \pm 0.20$ & $1.26 \pm 0.20$ \\
\hline MA & 300 & & $5.33 \pm 0.28$ & $0.82 \pm 0.19$ & $1.92 \pm 0.13$ & $1.33 \pm 0.11$ & $0.86 \pm 0.15$ & $0.76 \pm 0.15$ & $0.80 \pm 0.26$ & $1.34 \pm 0.17$ & $1.36 \pm 0.07$ \\
\hline MA & 1000 & & $5.51 \pm 0.27$ & $0.86 \pm 0.25$ & $1.86 \pm 0.12$ & $1.23 \pm 0.13$ & $0.83 \pm 0.11$ & $0.81 \pm 0.22$ & $0.73 \pm 0.15$ & $1.36 \pm 0.21$ & $1.37 \pm 0.04$ \\
\hline Control & --- & Male & $6.26 \pm 0.15$ & $0.74 \pm 0.05$ & $2.13 \pm 0.01$ & $1.13 \pm 0.28$ & $0.56 \pm 0.05$ & $0.79 \pm 0.25$ & $0.72 \pm 0.24$ & 1.270 .18 & $1.28 \pm 0.13$ \\
\hline MA & 100 & & $5.16 \pm 0.37$ & $0.67 \pm 0.58$ & $2.06 \pm 0.07$ & $1.15 \pm 0.05$ & $0.62 \pm 0.16$ & $0.77 \pm 0.17$ & $0.67 \pm 0.05$ & $1.29 \pm 0.24$ & $1.24 \pm 0.11$ \\
\hline MA & 300 & & $5.17 \pm 0.39$ & $0.65 \pm 0.17$ & $2.04 \pm 0.06$ & $1.19 \pm 0.67$ & $0.66 \pm 0.15$ & $0.69 \pm 0.23$ & $0.73 \pm 0.16$ & $1.37 \pm 0.22$ & $1.32 \pm 0.23$ \\
\hline MA & 1000 & & $5.34 \pm 0.36$ & $0.83 \pm 0.20$ & $2.13 \pm 0.08$ & $1.07 \pm 0.14$ & $0.56 \pm 0.37$ & $0.87 \pm 0.06$ & $0.85 \pm 0.17$ & $1.36 \pm 0.16$ & $1.36 \pm 0.29$ \\
\hline
\end{tabular}

$n=6$. Values are mean \pm SD. There was no significant change in food consumption of rats during treatment

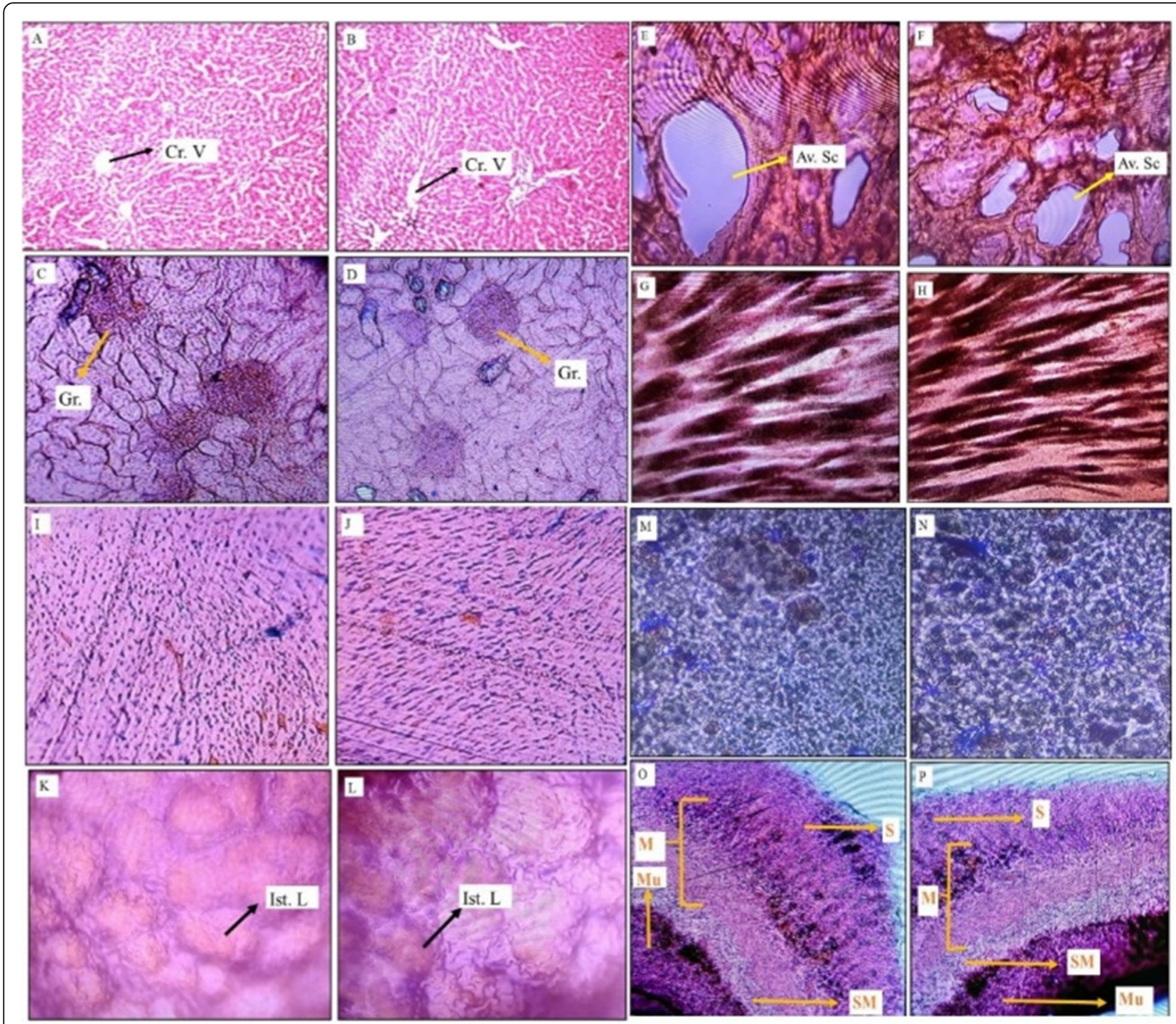

Fig. 7 Photomicrograph of organ sections of rats administered with normal saline and MA (1000 mg/kg) for 28 days. Histomorphologies of normal group rats-A, liver; C, kidney; E, alveolar sac; G, brain; I, cardiac cells; K, pancreatic cells; $M$, spleen; O, stomach. Histomorphologies of $M$. alba treated rats—B, liver; D, kidney; F, alveolar sac; H, brain; J, cardiac cells; L, pancreatic cells; N, spleen; P, stomach. Cr. V central vein; Gr. glomerulus; Av. Sc alveolar sac; Ist. L islet cells of Langerhans; Mu mucosa; SM sub mucosa; M muscularis; S serosa 
any associated neurochemical estimations; to understand the exact mechanism of action and extend the results further, it is necessary to carry out estimations of the neurotransmitter levels in the brain.

\author{
Abbreviations \\ MA: $70 \%$ methanol extract of M. alba L. fruits; OECD: Organization for \\ Economic Cooperation and Development; HPTLC: High-performance thin \\ layer chromatography; CPCSEA: Committee for the Purpose of Control and \\ Supervision of Experiments on Animals; IAEC: Institutional Animal Ethics \\ Committee; LDB: Light dark box; AST: Aspartate transaminase; ALT: Alanine \\ transaminase
}

\section{Acknowledgements}

The authors are grateful to all the laboratory technicians for their help and support.

\section{Details of plant source}

The mature fruits of Morus alba L. (Family: Moraceae) were collected from Dibrugarh University campus, Assam, India, during the month of March 2018. The plant was identified and authenticated by the Botanical Survey of India Eastern Regional Centre, Shillong (No.: BSI/ERC/2018/Tech/468, dated 22 October 2018). A voucher specimen with accession number DU/PSC/HRB-04/ Sept'2018 was deposited at Department of Pharmaceutical Sciences, Dibrugarh University, Assam, India.

\section{Authors' contributions}

AP: carried out the extraction, characterization of the plant extract and was the major contributor in writing the manuscript. KZ: supervisor who guided in characterization of the secondary metabolites. AS: co-supervisor who proposed and monitored the pharmacological study. All the authors have read and approved the manuscript.

\section{Funding}

This research did not receive any specific grant from funding agencies in the public, commercial or not-for-profit sectors.

\section{Availability of data and materials}

All data and materials are available upon request.

\section{Ethics approval and consent to participate}

The experiments involving animals were performed in accordance with the guidelines of Committee for the Purpose of Control and Supervision of Experiments on Animals (CPCSEA) (approval no. IAEC/DU/166, dtd. 10.12.2018)

\section{Consent for publication}

Not applicable

\section{Competing interests}

The authors declare that they have no competing interests.

Received: 4 July 2020 Accepted: 10 September 2020

Published online: 18 November 2020

\section{References}

1. WHO (2000) General guidelines for methodologies on research and evaluation of traditional medicine. World Health Organization, Geneva

2. Ernst E (1998) Harmless herbs ? A review of the recent literature. Am J Med 104:170-178

3. Jordan SA, Cunningham DG, Marles RJ (2010) Assessment of herbal medicinal products : challenges, and opportunities to increase the knowledge base for safety assessment. Toxicol Appl Pharmacol 243:198-216

4. Popat A, Shear NH, Malkiewicz I, Stewart MJ, Steenkamp V, Thomson S, Neuman MG (2001) The toxicity of Callilepis laureola, a South African traditional herbal medicine. Clin Biochem 34:229-236

5. Gupta RC, Srivastava A, Lall R (2018) Toxicity potential of nutraceuticals. Orazio Nicolotti (ed.), Computational toxicology: methods and protocols, methods in molecular biology. https://doi.org/10.1007/978-1-4939-7899-1 18.
6. Tilburt JC, Kaptchuk TJ (2008) Herbal medicine research and global health: an ethical analysis. Bull World Health Organ 86:594-599 https://doi.org/10. 2471/BLT.07.042820

7. Srivastava S, Kapoor R, Thathola A, Srivastava RP (2006) Nutritional quality of leaves of some genotypes of mulberry (Morus alba). Int J Food Sci Nutr. https://doi.org/10.1080/09637480600801837

8. Katsube T (2006) Food chemistry antioxidant flavonol glycosides in mulberry (Morus alba L.) leaves isolated based on LDL antioxidant activity. Food Chem 97:25-31

9. Anonymous (2001) The wealth of India, a dictionary of Indian raw materials, 7th edn. Council of Scientific and Industrial Research, New Delhi

10. Wang W, Zu Y, Fu Y, Efferth T (2012) In vitro antioxidant and antimicrobial activity of extracts from Morus alba L. leaves, stems and fruits. Am J Chin Med 40:349-356

11. Ullah N, Khan MA, Khan S, Ahmad H, Asif AH, Khan T (2016) Nephroprotective potential of Morus alba, a prospective experimental study on animal models. J Pharm Biol 54:530-535

12. Chen H, Yu W, Chen G, Meng S, Xiang Z, He N (2018) Antinociceptive and antibacterial properties of anthocyanins and flavonols from fruits of black and non-black mulberries. Molecules 23:13-15

13. Jiao $Y$, Wang $X$, Jiang $X$, Kong F, Wang S, Yan C (2017) Antidiabetic effects of Morus alba fruit polysaccharides on high-fat diet- and streptozotocininduced type 2 diabetes in rats. J Ethnopharmacol 199:119-127

14. Kim HG, Ju MS, Shim JS, Kim MC, Lee S, Huh Y, Kim SY, Oh MS (2010) Mulberry fruit protects dopaminergic neurons in toxin-induced Parkinson's disease models. Br J Nutr 104:8-16

15. Gu PS, Moon M, Choi JG, Oh MS (2017) Mulberry fruit ameliorates Parkinson's-disease-related pathology by reducing a-synuclein and ubiquitin levels in a 1-methyl-4-phenyl-1,2,3,6-tetrahydropyridine/probenecid model. J Nutr Biochem 39:15-21

16. Seo KH, Lee DY, Jeong RH, Lee DS, Kim YE, Hong EK, Kim YC, Baek NI (2015) Neuroprotective effect of prenylated arylbenzofuran and flavonoids from Morus alba fruits on glutamate-induced oxidative injury in HT22 hippocampal cells. J Med Food 18:403-408

17. Kaewkaen P, Tong-Un T, Wattanathorn J, Muchimapura S, Kaewrueng W, Wongcharoenwanakit S (2012) Mulberry fruit extract protects against memory impairment and hippocampal damage in animal model of vascular dementia. Evid Based Complement Alternat Med https://doi.org/10.1155/ 2012/263520

18. Kang TH, Hur JY, Kim HB, Ryu JH, Kim SY (2006) Neuroprotective effects of the cyanidin-3-O- $\beta$-D-glucopyranoside isolated from mulberry fruit against cerebral ischemia. Neurosci Lett 391:122-126

19. Yang X, Yang L, Zheng H (2010) Hypolipidemic and antioxidant effects of mulberry (Morus alba L.) fruit in hyperlipidaemia rats. Food Chem Toxicol 48:2374-2379

20. Sadiq M, Nazir A, Schroe K (2008) Morus alba L. nature's functional tonic. Trends Food Sci Technol 19:505-512

21. Natić MM, Dabić D, Papetti A, Fotirić Akšić MM, Ognjanov V, Ljubojević M, Tešić ŽL (2015) Analysis and characterisation of phytochemicals in mulberry (Morus alba L.) fruits grown in Vojvodina, North Serbia. Food Chem 171 128-136

22. OECD, 425 (2008) Guidelines for testing of chemicals: acute oral toxicity- up and down procedure. OECD, Paris

23. OECD, 424 (2008) Guidelines for testing of chemicals: neurotoxicity study in rodents. OECD, Paris

24. Shakya A, Chatterjee SS, Kumar V (2014) A comparative pharmacological study with a Fumaria indica extract and monomethyl-fumarate. Pharmanutrition. https://doi.org/10.1016/j.phanu.2013.11.049

25. Box BM, Saudino D, Mogenson GJ (1978) Light-dark rhythms and drinking behavior in the rat. Behav Biol 24:107-112

26. Jurek B, Slattery DA, Maloumby R, Hillerer K, Koszinowski S, Neumann ID, Van den Burg EH (2012) Differential contribution of hypothalamic MAPK activity to anxiety-like behaviour in virgin and lactating rats. PLoS One 7:1-9

27. Shakya A, Chaudhary SK, Bhat HR, Gogoi N, Ghosh SK (2019) A rapid high-performance thin-layer chromatographic method to estimate quercetin in Benincasa hispida (Thunb.) Cogn. fruit pulp. JPC- J Planar Chromat 32:467-474

28. Shakya A, Gogoi N, Chaudhary SK, Bhat HR, Ghosh SK (2019) Development and validation of a high-performance thin-layer chromatography method for the quantification of rutin in the fruit pulp of Benincasa hispida (Thunb.) Cogniaux. JPC- J Planar Chromat 32:371-377 
29. Petroczi A, Taylor G, Naughton DP (2011) Mission impossible? Regulatory and enforcement issues to ensure safety of dietary supplements. Food Chem Toxicol 49:393-402

30. Poppenga RH (2010) Poisonous plants. Mol Clin Environ Toxicol 100:123175

31. Fred-Jaiyesimi AA, Ajibesin KK (2012) Ethnobotanical survey of toxic plants and plant parts in Ogun State, Nigeria. Int J Green Pharm 6:174-179

32. Prakash O, Kumar A, Kumar P, Ajeet A (2013) Anticancer potential of plants and natural products: a review. Am J Pharmacol Sci 1:104-115

33. Asare GA, Gyan B, Bugyei K, Adjei S, Mahama R, Addo P, Otu-Nyarko L, Wiredu EK, Nyarko A (2012) Toxicity potentials of the nutraceutical Moringa oleifera at supra-supplementation levels. J Ethnopharmacol 139:265-272

34. Lowry CA, Johnson PL, Hay-Schmidt A, Mikkelsen J, Shekhar A (2005) Modulation of anxiety circuits by serotonergic systems. Stress. 8:233-246

35. Lee MY, Shin IS, Seo CS, Kim JH, Han SR, Shin HK (2012) Subchronic oral toxicity studies of the traditional herbal formula Bangpungtongseong-san in Crl: CD (SD) rats. J Ethnopharmacol 144:720-725

36. Mukinda JT, Syce JA (2007) Acute and chronic toxicity of the aqueous extract of Artemisia afra in rodents. J Ethnopharmacol 112:138-144

37. Mahmoodzadeh Y, Mazani M, Rezagholizadeh L (2017) Hepatoprotective effect of methanolic Tanacetum parthenium extract on CCl4-induced liver damage in rats. Toxicol Rep https://doi.org/10.1016/j.toxrep.2017.08.003

38. Rahman MF (2001) Effects of vepacide (Azadirachta indica) on aspartate and alanine aminotransferase profiles in a subchronic study with rats. Hum Exp Toxicol 20:243-249

39. Li X, Luo Y, Wang L, Li Y, Shi Y, Cui Y, Xue M (2010) Acute and subacute toxicity of ethanol extracts from Salvia przewalskii Maxim in rodents. J Ethnopharmacol 131:110-115

\section{Publisher's Note}

Springer Nature remains neutral with regard to jurisdictional claims in published maps and institutional affiliations.

\section{Submit your manuscript to a SpringerOpen ${ }^{\circ}$ journal and benefit from:}

- Convenient online submission

- Rigorous peer review

- Open access: articles freely available online

- High visibility within the field

- Retaining the copyright to your article

Submit your next manuscript at $\boldsymbol{\nabla}$ springeropen.com 